\title{
An ontology-based universal design knowledge support system
}

\author{
Yasemin Afacan*, Halime Demirkan ${ }^{1}$ \\ Department of Interior Architecture and Environmental Design, Faculty of Art, Design and Architecture, Bilkent University, 06800 Bilkent, Ankara, Turkey
}

\section{A R T I C L E I N F O}

\section{Article history:}

Received 11 May 2007

Received in revised form 6 January 2011

Accepted 6 January 2011

Available online 13 January 2011

\section{Keywords:}

Computer-assisted design tool

Conceptual design phase

Cognitive design strategy

Universal design

Ontology

\begin{abstract}
A B S T R A C T
An effective and efficient knowledge support system is crucial for universal design process, as it has become a major design issue in the last decade with the growth of the elderly population and disabled people. There are a limited number of CAD investigations on the nature of knowledge processing that supports the cognitive activities of universal design process. Therefore, this paper proposes an ontology-based computer-assisted universal design (CAUD) plug-in tool that supports designers in developing satisfactory universal design solutions in the conceptual design phase. The required knowledge processing and representation of the developed tool is motivated by the ontological language. It is based on the multiple divergence-convergence cognitive strategies and cognitive needs of designers in the analysis/ synthesis/evaluation operations. The CAUD plug-in tool is the first attempt to interface the universal design knowledge ontologically and respond to the requirements of conceptual design phase. According to the user acceptance study, the tool is assessed as useful, understandable, efficient, supportive and satisfactory.
\end{abstract}

(c) 2011 Elsevier B.V. All rights reserved.

\section{Introduction}

Architectural design process is composed of a series of goal oriented cognitive activities. Although the final goal is ill-defined initially, the subgoals have to be well-defined throughout the design process [13]. The suitability of the design strategy and the efficiency of the knowledge support system determine the level of creativity and the quality of the design process [26]. Since "designers cannot retain all the information they need to solve complex design problems in their heads, so they must retrieve that information from external sources, including colleagues, documents, drawings, models and databases" [7, p. 173]. In the last 20 years, there had been attempts to develop an ideal knowledge-based computational design support system that assists designers by providing databases, storing design goals and predicting the performances of alternative solutions [10]. However, there are many discussions on the suitability of these support systems to the conceptual design phase $[25,38,59]$. Commercially available CAD tools were far from being promising for covering the requirements for conceptual design phases since they were more suitable for the detailed design phase in the early years [43]. Nowadays, the conceptual phase as the most vigorous, dynamic, informal, complex and creative phase is the least understood and supported by the CAD systems. "Current CAD tools push designers in precisely the wrong direc-

\footnotetext{
* Corresponding author. Tel: +90 312290 1515; fax: +90 3122664136 .

E-mail addresses: yasemine@bilkent.edu.tr(Y. Afacan), demirkan@bilkent.edu.tr (H. Demirkan).

1 Tel.: +90 312290 1762; fax: +90312266 4136 .
}

tion, encouraging users to bypass the refinement process of creative and critical thought and go straight to the finished work" [11, p. 592]. Most CAD users are contended with the same tools in the conceptual phase that they use in the detailed design phase. Therefore, there is an urgent need to develop an efficient knowledge-based system that supports conceptual activities.

A suitable knowledge support system is also crucial for designing better built environments. In the last decade, the concept of universal design, which means creating products, environments and systems for all ages, abilities and sizes, has become a major design issue with the growth in the elderly population and disabled people [42]. Furthermore, the needs and demands of diverse population members, who are children, adult or disabled, vary considerably. For Mace [34], it includes not just people in wheelchairs, but also people with mobility, speech and hearing impairments, and with all diminished abilities, either temporary or permanent, that can be occurred over a person's life span, such as retardation, advanced age, or pregnancy. Thus, to overcome the inclusivity challenge in the design process, universal design has been studied extensively in various fields such as interior and product design, design education and many others [39]. However, there are a limited number of CAD studies on the nature of design cognition that supports an effective universal design knowledge acquisition in the conceptual phase. Most of the developed systems provide support for design representation, manipulation and transformation, but none of them explicitly support cognitive needs of architects. The relevant studies should go beyond specification of human dimensions, visualization of ergonomics data or task analysis tools. The importance of architectural design in the technological arena 
shows it has a specific domain for cognitive understanding of all dimensions of the real world. So, this study develops an ontology-based universal design support system for the conceptual phase. Since the ontological approach described as 'an explicit specification of a conceptualization' [22] is suitable for determining the specific features of a certain domain, it appears as a promising integration structure for this study. We propose a computer-assisted universal design (CAUD) plug-in tool that supports real world designers in applying a suitable design strategy for developing satisfactory solutions. In this respect, the overall aim of the research is to focus on how universal design knowledge ontologically relates itself to the methodological flow of design process. To the best of the authors' knowledge, this study is the initial evidence in architectural design literature that an ontologybased universal design knowledge support tool for the conceptual design phase. The research questions addressed by this study are:

1. How does a designer define a set of requirements, a sequence of design strategies and evaluate alternative solutions in the conceptual phase of the universal design process?

2. How does a designer retrieve and use the information from an ontology-based universal design knowledge domain including experts, design solutions and databases?

3. How does the dynamic nature of a CAD medium provide feedback to the designer in the conceptual design phase?

The outline of this paper is as follows: In Section 2, we review the literature on cognitive strategies of designers and their CAD usage in the conceptual phase. Section 3 addresses universal design knowledge processing and representation where an ontology-based model put forward with respect to an iterative design process. Section 4 introduces the proposed experimental system - CAUD plug-in tool - with user interfaces. In Section 5, the evaluation of the tool is conducted. Finally, Section 6 draws conclusions and mentions future work.

\section{Related works}

\subsection{Cognitive strategies of designers in the design process}

Research in cognitive psychology over the last three decades has largely concentrated on designers' interaction with the design process and their engagement with problem [16]. Although "there is a general lack of knowledge how designers actually design" [11, p. 592], designers should operate an effective strategy to increase the possibility of creating promising concepts as early as possible. Therefore, being consistent with 'designerly ways of thinking' [13] is the central issue for the success of a knowledge-based design support system. "Design strategy can be represented as metaknowledge, which is knowledge concerning how to use some domain knowledge, in the knowledge processing system for the design support" [24, p. 30]. In this study, the domain knowledge is universal design knowledge, which is primarily considered for interior design at the conceptual level, however, the experimental methodology has more general features and can be used similarly in various design applications. The conceptual decisions of designers come from the knowledge processing via the proposed CAUD tool.

A cognitive strategy is the general plan of a sequence of particular actions employed by a designer throughout the design process. However, its employment differs from one designer to the other based on subjective interpretations [16]. So, the design process can be considered as a convergent act that is composed of several divergent steps. The convergence based design strategy is concerned with selecting the most appropriate solution from alternatives while the divergence based one deals with producing a wide range of alternatives [12]. According to Cross [12], convergent thinkers are successful in selecting a feasible solution among alternatives and satisfying requirements of detailed design whereas "divergent thinkers are good at concept design and generation of a wide range of alternatives" (p. 144). In convergent thinking process, the problem is systematically explored in order to generate an optimum solution [29]. On the other hand, the divergent thinking process can be explained as the tendency of designer to suggest a variety of possible solutions until a satisfactory solution is generated [29]. However, the "activities in design do not take place in a predictable order, [and] the information dealt with cannot be foreseen" [57, p. 25]. It is not possible to use solely the convergence or divergence based strategy, particularly for the early stages of a design process. The dynamic nature of concept generation should be supported by an ideal strategy. In this respect, Liu et al. [32] proposed the multiple divergence-convergence based design strategy as an ideal approach for concept generation. Previously, many researchers focused on this strategy without naming it exactly as the multiple divergence-convergence approach. Fricke [20] investigated designers' tactics to find the most successful method for solution search and noticed that the multiple divergent and convergent activities have led to the most successful designs. Dorst and Cross [16] analyzed Maher et al.'s [37] co-evolution model in terms of the creativity in design process. They concluded that creative design is a matter of divergent and convergent steps together with the iterative process of analysis, synthesis and evaluation rather than first stabilizing the problem and then searching for a satisfactory solution. Since specifying a goal does not determine the way to perform a design task, it is important to carry out a process where many possible solutions can be explored and assessed for each task. As stated by Liikkanen and Perttula [31], idea generation is a phase where repeated analysis/synthesis cycles take place in investigating the problem decomposition. So, carrying out multiple divergent and convergent activities at each level of solution abstraction allows designer to generate a reasonable number of concepts. Especially, this strategy is helpful when designing with the CAD tools, where "the number of concepts can be considerably larger than the number that s/he can manually generate" [32, p. 348]. However, there is a very limited amount of literature available on knowledge-based tools stimulating an ideal strategy [27]. This study differs from the other approaches by seeking an ontology-based automated approach that relates multiple divergent and convergent strategies to the usage of domain knowledge, since the ontology-based information content is correlated more highly with human judgments compared to the other computation methods [51]. In this paper, we investigate how the universal design knowledge can be ontologically rearranged along the CAUD tool that is consistent with 'designerly way of thinking' [13].

\subsection{CAD usage in the conceptual design phase}

While CAD tools are being developed at an increasingly fast speed, the cognitive process in conceptual design is not well understood in the last three decades. Reviewing literature showed that from the beginning of 1990 s there are various approaches that have been attempted to solve conceptual problems with computational methods, such as a knowledge-based design decision support tool (KNODES) by Rutherford and Maver [50]; a software environment to support early phases in building design (SEED) by Flemming [19]; a CAD system for a knowledge-based support for architectural design (KAAD) by Carrara et al. [10]; the innovative conceptual design system by Loughborough University (LUCID) [59] and an interactive system for 2D and 3D conceptual drawings in architectural design (ArchiDNA) by Kwon et al. [28].

Among these attempts, there is a consensus on the issue that conventional CAD systems do not provide a suitable medium for 
conceptual design phase. A CAD system should assist designers from the initial phase of a design process. Furthermore, there should be a systematic management of activities through which alternatives can be explored and functional descriptions are converted into design configurations. Since divergent approaches increase the number of alternatives at each solution level, there is an increase in the total number of solutions at the end of the design process. However, solutions that fail to satisfy the major objectives can be discarded by divergent-convergent steps at each level to continue with manageable number of alternatives. Recently, Kurtoglu et al. [27] developed an automated conceptual design tool for choosing suitable design components. In this automated tool, firstly many feasible concepts are developed by using an online knowledge-base, and then they are automatically evaluated and ranked according to a list of predefined design rules. The basis of this automated approach is to extract design knowledge systematically and integrate it into a computational framework. However, in this study we employ the multiple divergence-convergence based strategy in developing a knowledge-based universal design support tool for the conceptual design phase, the CAUD plug-in tool (Fig. 1). The proposed framework of the plug-in tool is dynamic in nature while based on multiple strategies compared to the static nature of Kurtoglu et al.'s study [27]. Our approach also goes beyond other studies by handling the cognitive needs of designers in knowledge processing and representation, responding to drawing inputs and providing meaningful alternatives, rather than random solutions. As Mahalakshmi and Geetha [36] stated, ontologies should promote human cognition for the performance and accuracy of operation of knowledge-based systems.

\section{Universal design knowledge processing and representation}

A knowledge-based tool should provide a medium for effective knowledge processing and expressive knowledge representation [41]. Universal design knowledge processing and representation is a difficult task [53]. There is an important number of interacting design elements that should be considered [1]. Although the universal design principles inform designers about usable environments [54], they are not sufficient to generate promising alternatives. It is usually difficult to follow, organize, access and use them [45]. So, the extent of diverse user needs, relevant time and the way of integrating universal design requirements to architectural design process still remain largely unresolved $[3,4]$. There is no unique parameter that can be optimized. Rather, there are sets of requirements regarding each disability type. Moreover, designer must determine the relative importance and implementation order of each requirement because it is not possible to satisfy all of them equally. Thus, universal design knowledge pro-

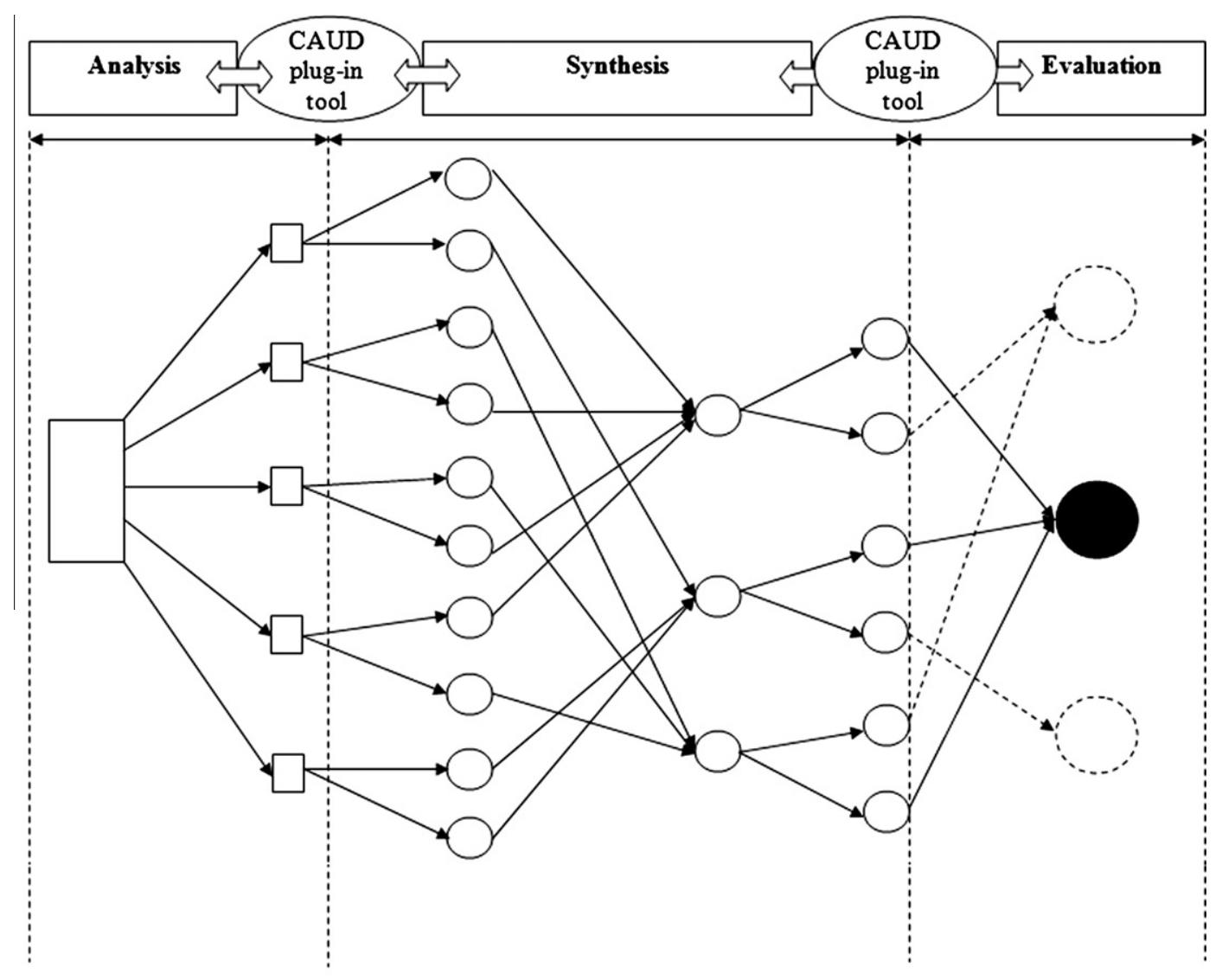

Problem

Selected solution altemative

Objective

Solution altemative

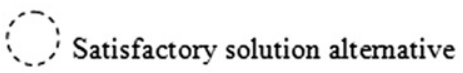

Fig. 1. The multiple divergence-convergence based strategy employed for the CAUD plug-in tool. 
cessing and representation should be considered in relation to correlations between different types of guidelines, user feedbacks and cases.

In this context, this study proposes a knowledge support system based on ontology to deal with the domain-specific knowledge, because "ontology is becoming the pivotal methodology to represent domain-specific conceptual knowledge" [23, p. 443]. In this case, the domain is universal design in architectural design context. The ontology of this domain includes concepts such as accessible space layouts, comfortable furniture, circulation elements and many others. Ontologies have advantage over conventional data schemas; they are highly flexible and permitting modifications and extensions [15]. This enables the knowledge-based tool to define the semantics of ontological concepts. The ontology for universal design in this case is a formal vocabulary for defining universal design requirements. It offers knowledge retrieval based on access to the proposed features of the CAUD plug-in tool. This helps to overcome the difficulties that arise from working out a collection of various user data and constraints within the network of solutions.

In terms of knowledge representation, the development of ontology supports representation and customization of multiple knowledge types. It provides a means for representing universal design knowledge as a continuous process of designer's cognitive interactions between problem formulation and solution generation. Although design activity is generally explained under the model of analysis-synthesis-evaluation in the literature [9], this study defines universal design representation as an iterative process composed of the three main operations: (1) Defining a set of objectives (analysis), (2) generating alternative design solutions in relation to objectives (synthesis),(3) evaluating these alternatives (evaluation). However, these operations are not executed sequentially. They are thoroughly intertwined. The sequence is dependent on the cognitive operations of designer that oscillates between their cognitive abilities of the designer and analysis-synthesis-evaluation iterative process [13]. An ontology-based representation leads to capture and reuse universal design knowledge during this iterative process. It has the following benefits: (i) greater access to knowledge, (ii) more efficient problem handling, (iii) more promising integration structure between each operation and (iv) reduced time for knowledge indexing and searching. So, like O3R (Ontology-based Rules Retrieval and Rummaging) proposed by Becker and Vanzin [6], this ontology-based system is user-centric and provides an explicit representation and manipulation of domain knowledge, but in addition this study encompasses the cognitive abilities of designers. Fig. 2 illustrates the proposed ontology-based knowledge processing and representation model. The following sections define briefly the requirements of each operation with respect to ontology.

\subsection{Analysis}

Analysis operation as the initial part of the conceptual design process requires defining a list of objectives as design specifications. Ozkaya and Akin [44] described design specification and development as being parallel activities since design act is a cyclic process, where alternatives are checked against the initial set of objectives, and the set of objectives are redefined for the subsequent steps. Examining the literature on universal design problem-solving emphasized also the importance of analysis operation [13]. As the designer conducts an analysis operation, the user ontologies can be built up by specifying the design objectives that set the limits to the solution space, and indicate the preferred solutions. Since the initial definition of each objective can critically affect the solution in later phases, backtracking of definitions can be achieved by ontological semantics. Ontologies attempt to precisely define each objective (e.g. what space dimensions are, how the space is furnished), and express it through relations. Thus, an ontology-based approach provides formal definitions for problem descriptions and can make automated inferences about relationships among objectives (e.g. how furniture is related to space dimensions).

\subsection{Synthesis}

Synthesis operation is generating solution alternative solutions with respect to the specified requirements. Roozenburg and Eekels [49] defined synthesis as the moment of externalization and description of an idea either in the form of a sketch, drawing or model. During synthesis "divergent and convergent activities alternate constantly, because there is never just one solution" [49, p. 176]. Therefore, it requires a successful linking mechanism between each requirement and alternative. Ontologies can support synthesis operation by establishing shared links between concepts, attributes and solutions. Another aspect for synthesis operation is the importance of critics. In this respect, a wiki could be built around ontology that allows users to share ideas in a collaborative content criticize alternative solutions and discuss them through an Internet environment.

\subsection{Evaluation}

Evaluation is assessing and comparing the expected performances of an emerging solution with the specified objectives [9]. "The final product is an appropriate combination of carefully selected sub-solutions" [7, p. 173]. However, evaluation and selection of the most satisfactory solution from a wide range of

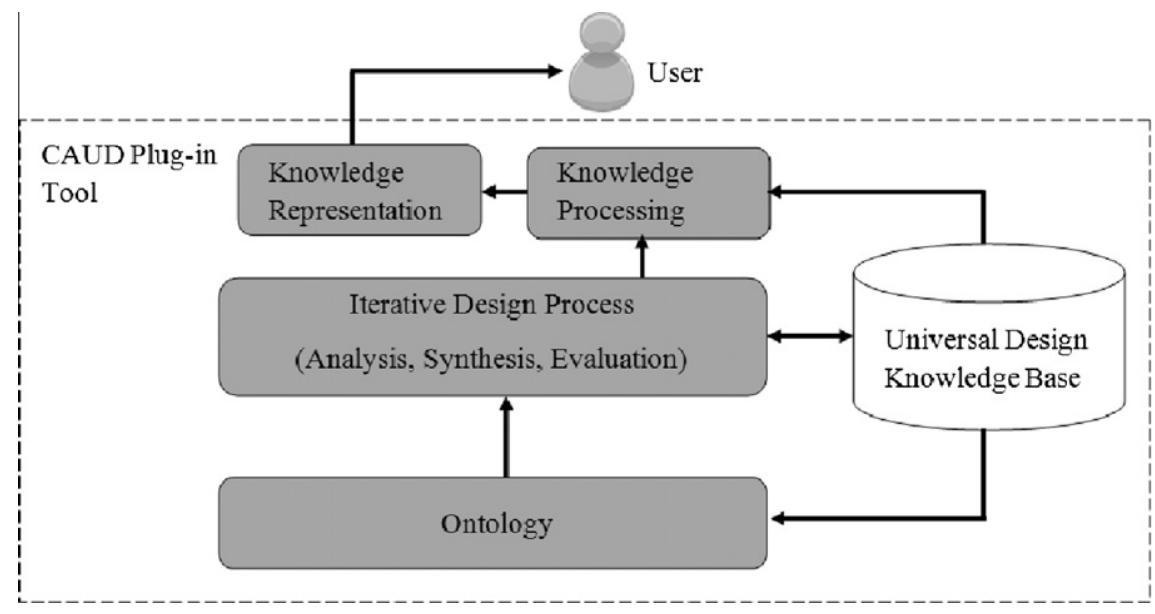

Fig. 2. The proposed ontology-based knowledge processing and representation model. 
solution alternatives is often subjective. "Designers in practice would find it difficult to complete the evaluation job because of the very large number of designs to be evaluated" [32, p. 247]. Although, previous studies developed many universal design assessment methods, such as weighted objectives (five-point rating scale for universal design performance measures [55,56]), factor scale scores (Post-Occupancy-Evaluation (POE) and Building Performance Evaluation (BPE) [46]), or checklists (universal design audit checklist [30]), they are provided in a non-CAD medium and are insufficient for conceptual design phase. By using ontology language, universal design concepts, their relationships and levels of priority could be defined in terms of objective assessments rather than subjective and experience-based. It can provide automated inferences about relationships among concepts. Since ontologies enable to decompose objects into smaller and interacting attributes, they can provide detailed assessments and comparisons of universal design alternatives in terms of different parameters such as dimension, material, texture and light.

\section{An experimental system: the computer-assisted universal design (CAUD) plug-in tool}

An experimental system based on ontology is developed to overcome all the above-explained deficiencies of universal design knowledge processing and representation during analysis, synthesis and evaluation operations. The proposed CAUD plug-in tool has user interfaces that facilitate creation, modification and display of the relevant knowledge. SketchUp 8, three-dimensional conceptual design software program (www.sketchup.com), is used as a CAD package for the study because of the flexibility and suitability to creative thinking of conceptual design activities. It also provides a web-based collaboration environment with a database library named Google 3D Warehouse. The CAUD plug-in tool is activated by choosing the relevant item from the 'Plug-ins' menu. Its' user interface is composed of message boxes, dialog boxes and web dialogs. Fig. 3 illustrates the flowchart of the six components of the CAUD plug-in tool and data flows among them throughout analysis/synthesis/evaluation operations. The capabilities of these components add new knowledge processing and representation facilities to SketchUp that address cognitive challenges of the universal design process. They are acting as a key mechanism that supports the digital information flow from analysis to synthesis operation and from synthesis to evaluation operation. Using ontologies also facilitates effective and efficient knowledge input and retrieval.

In the analysis operation, the plug-in tool increases the effectiveness in diagnosing and formulating a problem, completing a to-do checklist and communicating with final design. In the synthesis operation, the tool supports generation of universal design alternatives by providing relevant dimensional standards and design guidelines, examples of previous case studies and critics from other designers. Although it is claimed that "expert systems are inadequate in situations, where it is difficult to capture sufficient domain knowledge, and leave the human out of the decision process" [17, p. 126], this developed tool is not an expert system that dominates the universal design process. The knowledge processing and representation is supported through critics. The web-based collaboration environment of SketchUp provides a suitable medium for supporting the collaborative universal design knowledge formation. The semantic wiki system of the Google 3D Warehouse links both graphical and verbal means of guidelines, standards and exemplary cases to each other that makes easy for real world designers to share, search and collaborate securely. Since "almost none of the well-known knowledge engineering methodologies or tools provide support for collaborative work" [52, p. 12], the plug-in tool provides only basic collaborative features as a part of its ontological approach, e.g. annotations, views and notification of changes. Ontologies can provide two main collaboration modes; synchronous-changes made by a user that are immediately visible to other users and asynchronous-changes that are visible later [21]. Our plug-in tool is based on asynchronous mode that does not allow users to apply changes in a single ontology during the synthesis. In the evaluation operation, the tool helps to refine solution alternatives by assessing how well the generated solution alternative satisfies the dimensional standards and universal design principles. In the study, the current implementation of these capabilities of the plug-in tool is only limited to interior design applications. The following five sections explain each capability in detail and illustrate their interfaces for a universal kitchen case study.

\subsection{Universal design to-do list}

Universal design to-do list provides a list of the specified universal design requirements and helps to organize/store/present each requirement in an appropriate format. It includes a checkbox that acts as a control mechanism to keep track of the status of each requirement task. It works as a passive reminder for designers to complete unfinished requirement tasks or add new tasks emerging from solution alternatives. As design solution nears completion, a to-do list check can be performed based on the set of defined objectives to point out the possible flaws in requirement specification. In this respect, design process and representation of requirements are carried out as parallel activities within the CAUD environment. Briefly, a to-do list item contains a list of objective descriptions with assigned status, date and the add/delete buttons. Fig. 4 illustrates an exemplary universal design to-do list interface.

\subsection{Feedback from critiques}

Critique feedback assists designers through dimensional standards and design guidelines. It supplies the relevant universal design knowledge on dimensional standards via dialog boxes and design guidelines via message boxes. Dimensional standards provide the mandatory minimum technical specifications for a particular design element. Design guidelines deliver designers knowledge support as recommendations. They minimize effort and time to access relevant universal design knowledge processing and representation by storing the data within the drawing environment. Experiences on critiquing systems showed that active critics are not a perfect solution and can disrupt the designers' concentration [18]. In this respect, both the dialog and message boxes within the CAUD plug-in tool can be activated by selecting the relevant item from the Plugins menu of SketchUp. This study uses the knowledge domain of the International Best Practices in Universal Design [8], in which the Canadian accessibility codes for built environment are examined in relation to other international codes and the best practices are determined. Fig. 5 illustrates an exemplary dimensional standards interface for maneuvering diameter parameters and illumination design guidelines.

\subsection{Catalog of previous universal design solutions}

The catalog of previous universal solutions provides information to designers about case studies on universal design via a web dialog. The web dialog that interacts with web via a local html file opens a browser window and offers a mechanism to access both textual and graphical data. For the universal design domain, a case consists of relevant knowledge from the best universal design solutions regarding a person's disability need together with specific design solutions. Moreover, textual data is built in the form 


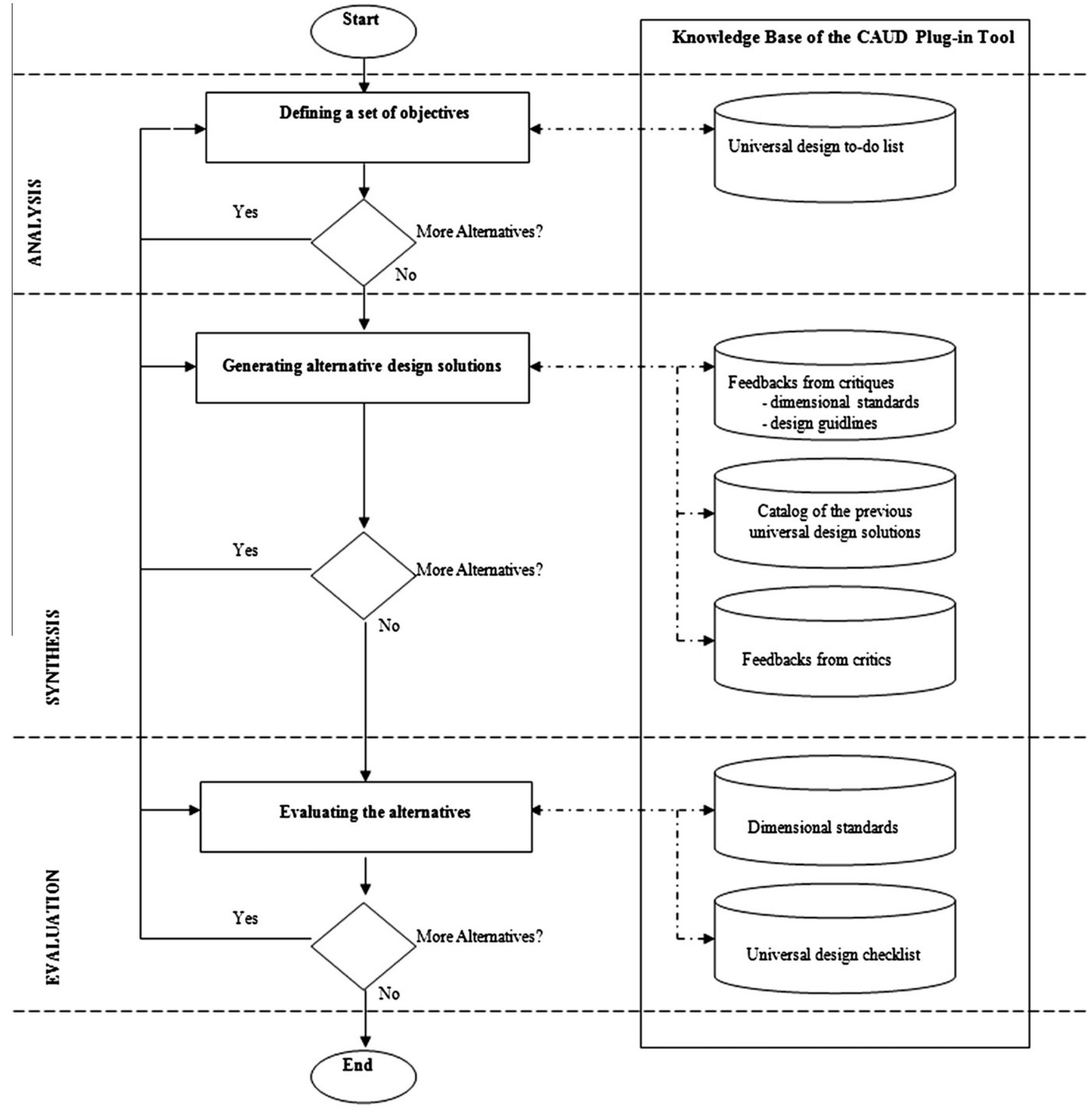

Information flow:

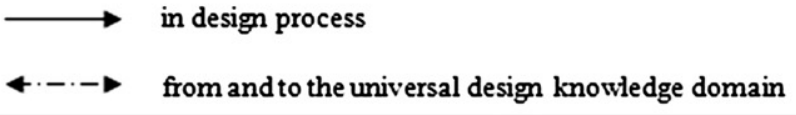

Fig. 3. The support scheme of the CAUD plug-in tool for the analysis-synthesis-evaluation operations.

of wikipages containing the special wiki markup. Each case is identified by a unique keyword, which is linked to an associated dimensional standard or design guideline interface. By this capability, designer is informed about architectural drawings, photographs, dimensional and/or textual information by choosing the appropriate keyword on the interface (Fig. 6a). Moreover, some of the recent case studies on universal design are available in the html format, and there are also some web site links that can be activated from this interface. Specific semantic annotations relate these text parts to the relevant web pages. Fig. $6 \mathrm{~b}$ shows a screenshot of a dialog box, which is opened by clicking the wiki markup of 'work aisle' and represents necessary textual data of an efficient work 


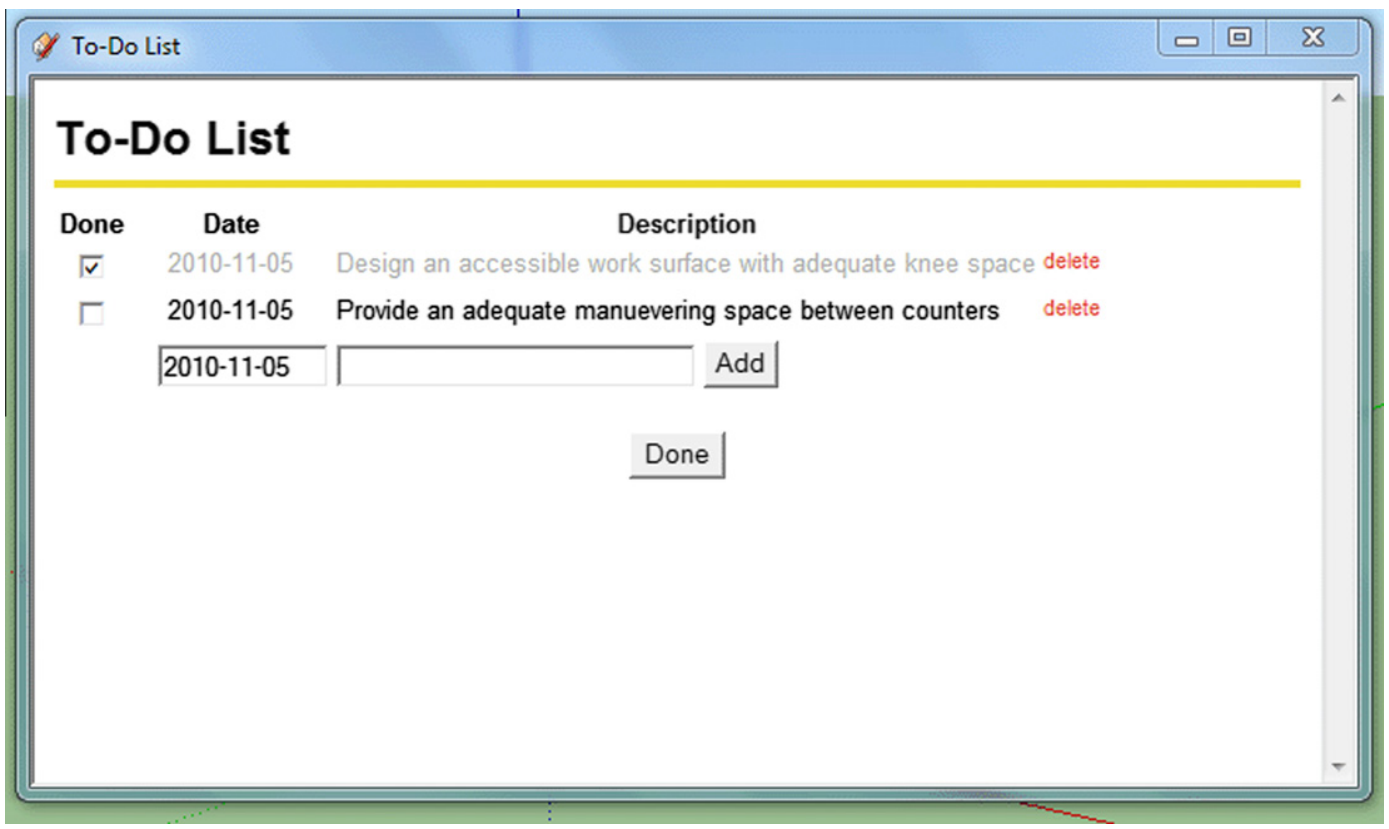

Fig. 4. An exemplary universal design to-do list interface for a universal kitchen case.

(a)

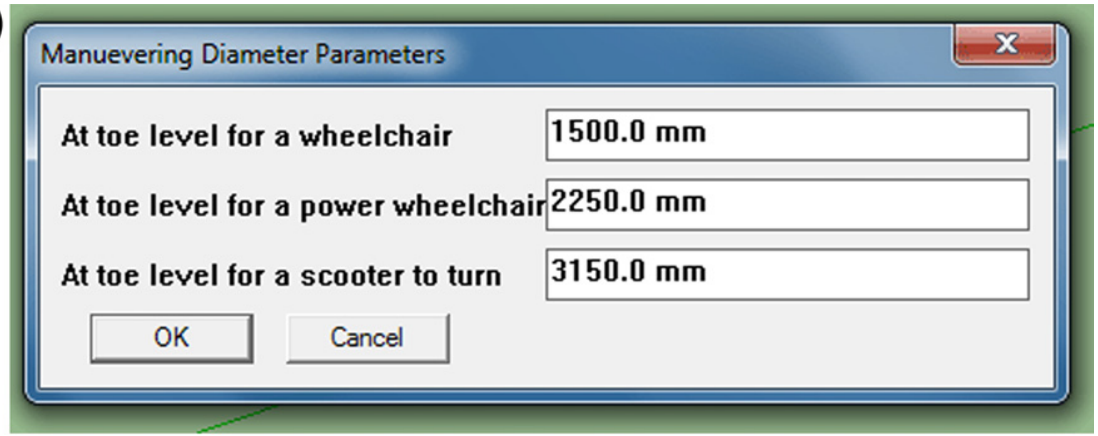

(b)

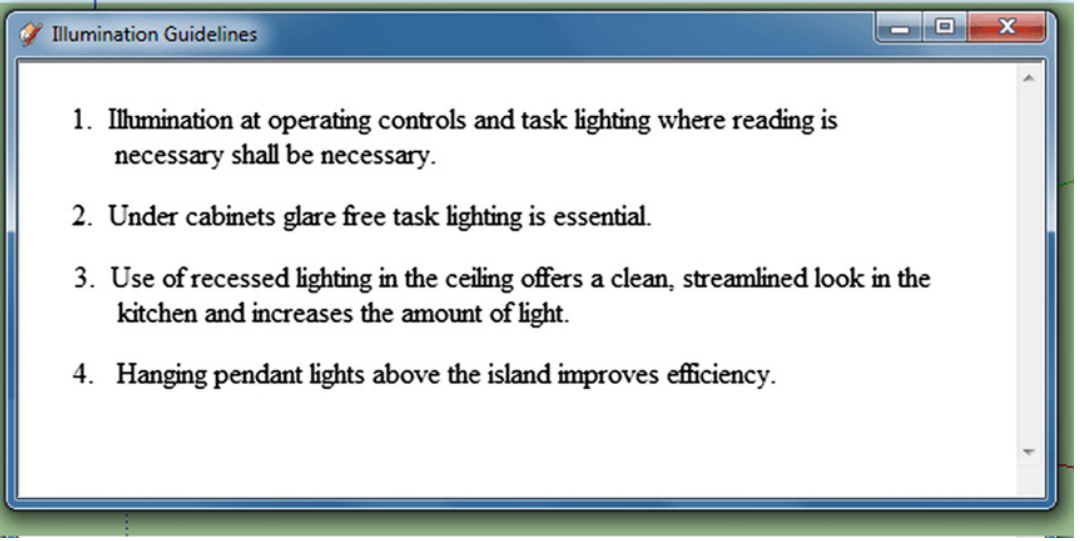

Fig. 5. An exemplary critique feedback dimensional standard interface (a) and the design guideline interface (b).

triangle from dimensional standards knowledge base of CAUD plug-in tool. So, the ontology here works as a semantic index of information that enables universal design knowledge connected across different capabilities of the plug-in tool. So, some parts of the catalog interface are related concepts of the knowledge base and thus, semantic annotations link these text parts to each other and to external websites.

\subsection{Feedback from critics}

Interactions with other designers in the design community guide the evolution of concept generation [48]. However "almost all design software still works largely for individuals. Critics given by other universal design experts have an important role in universal design process [47]. In this respect, the critic list interface is 
(a)

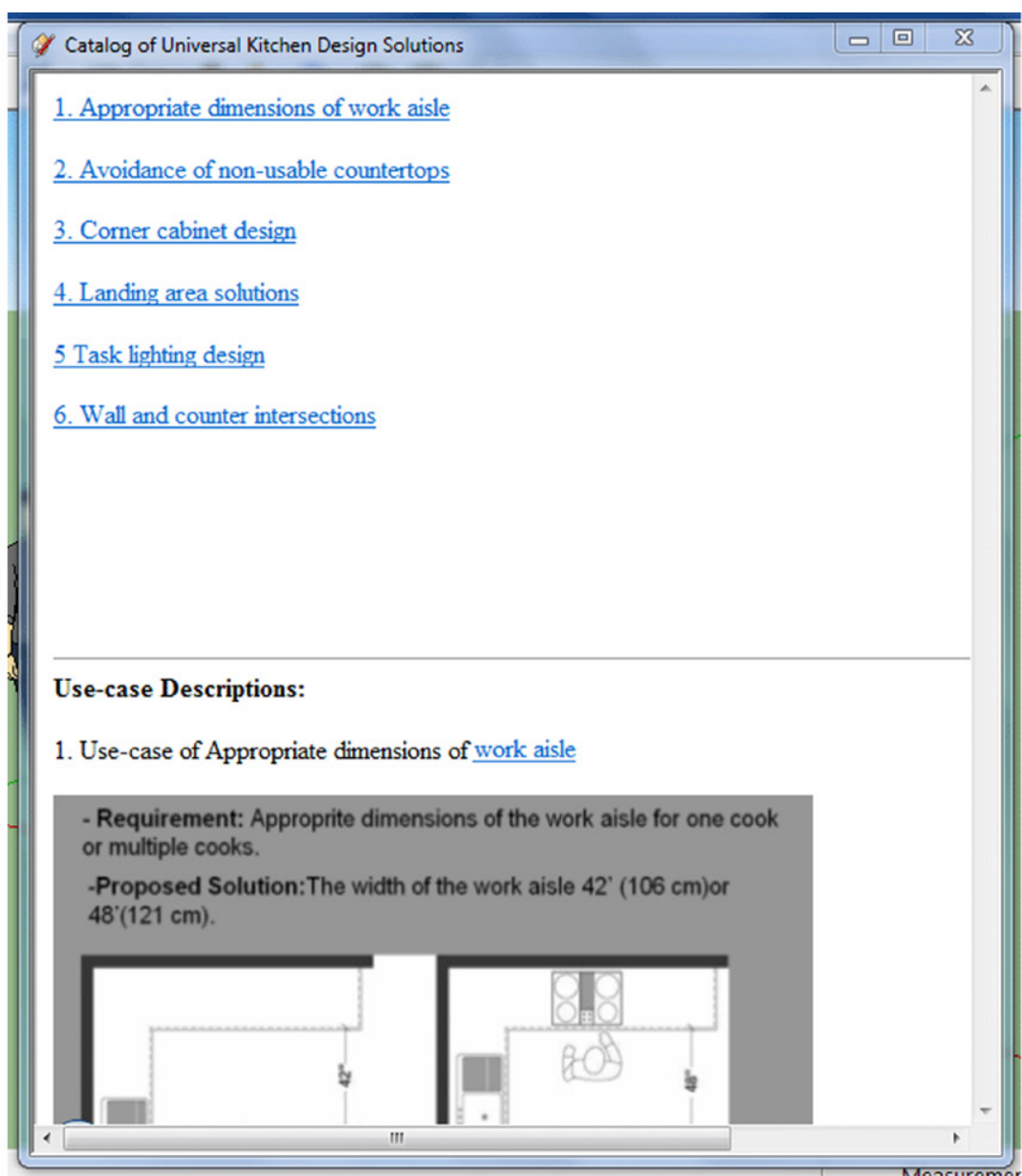

(b)

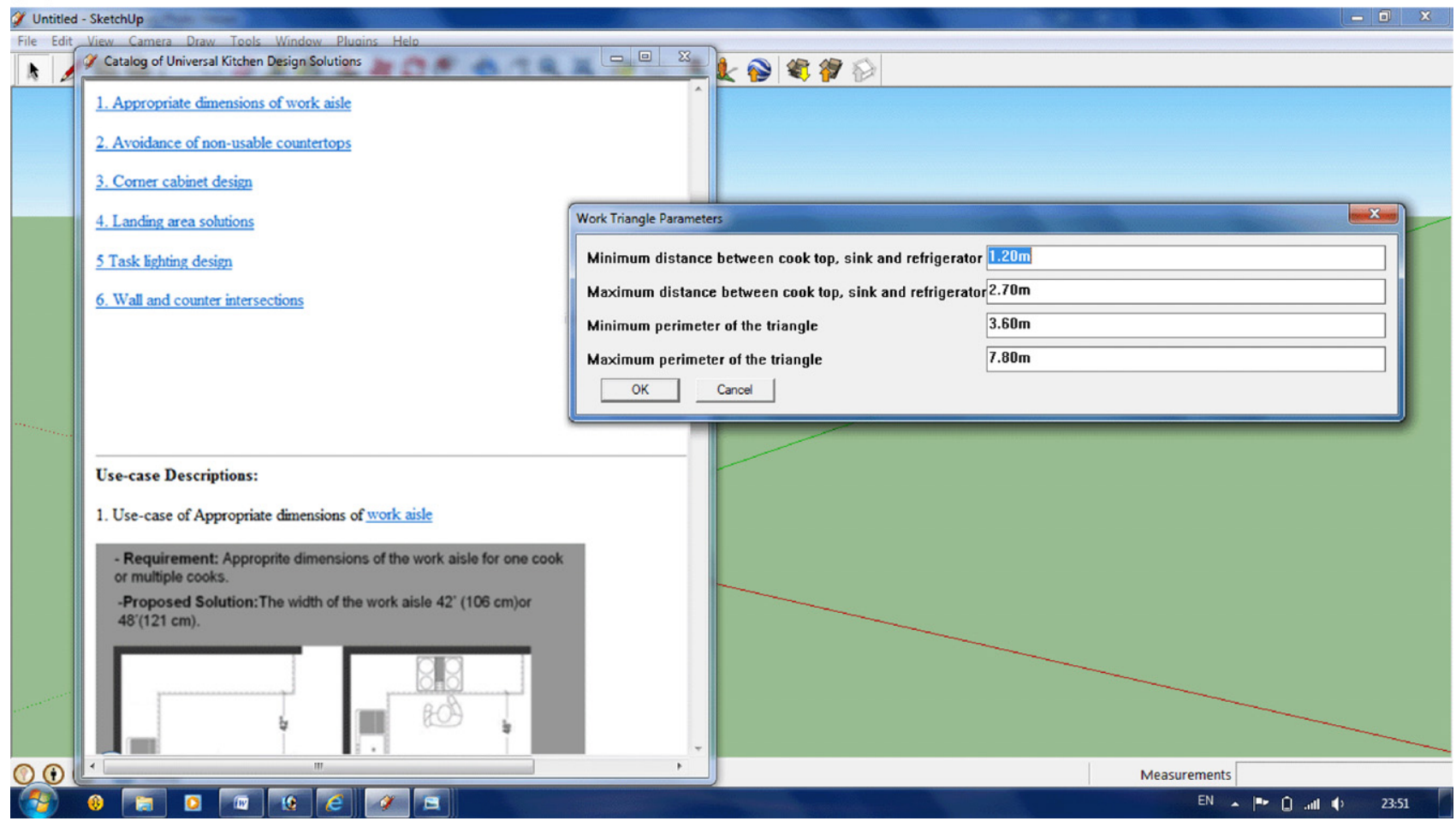

Fig. 6. An exemplary catalog of previous universal kitchen design solutions (a) and a screenshot of a dialog box (b) opened by clicking the wiki markup of 'work aisle'.

developed by adopting the World Wide Web as a collaboration platform. The Google 3D Warehouse, the web-based library, has become the main platform for electronic data sharing. The real world designers can upload or download universal design solution 
(a)

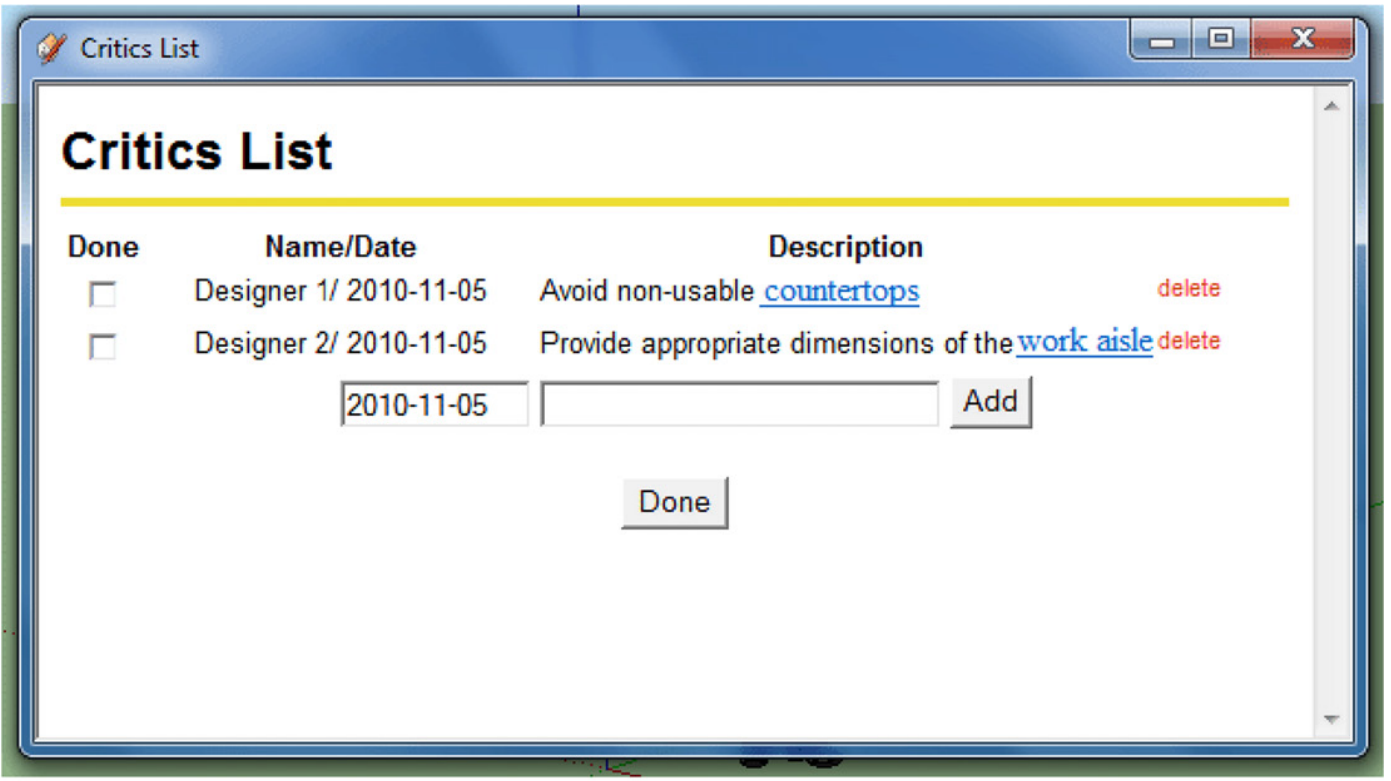

(b)

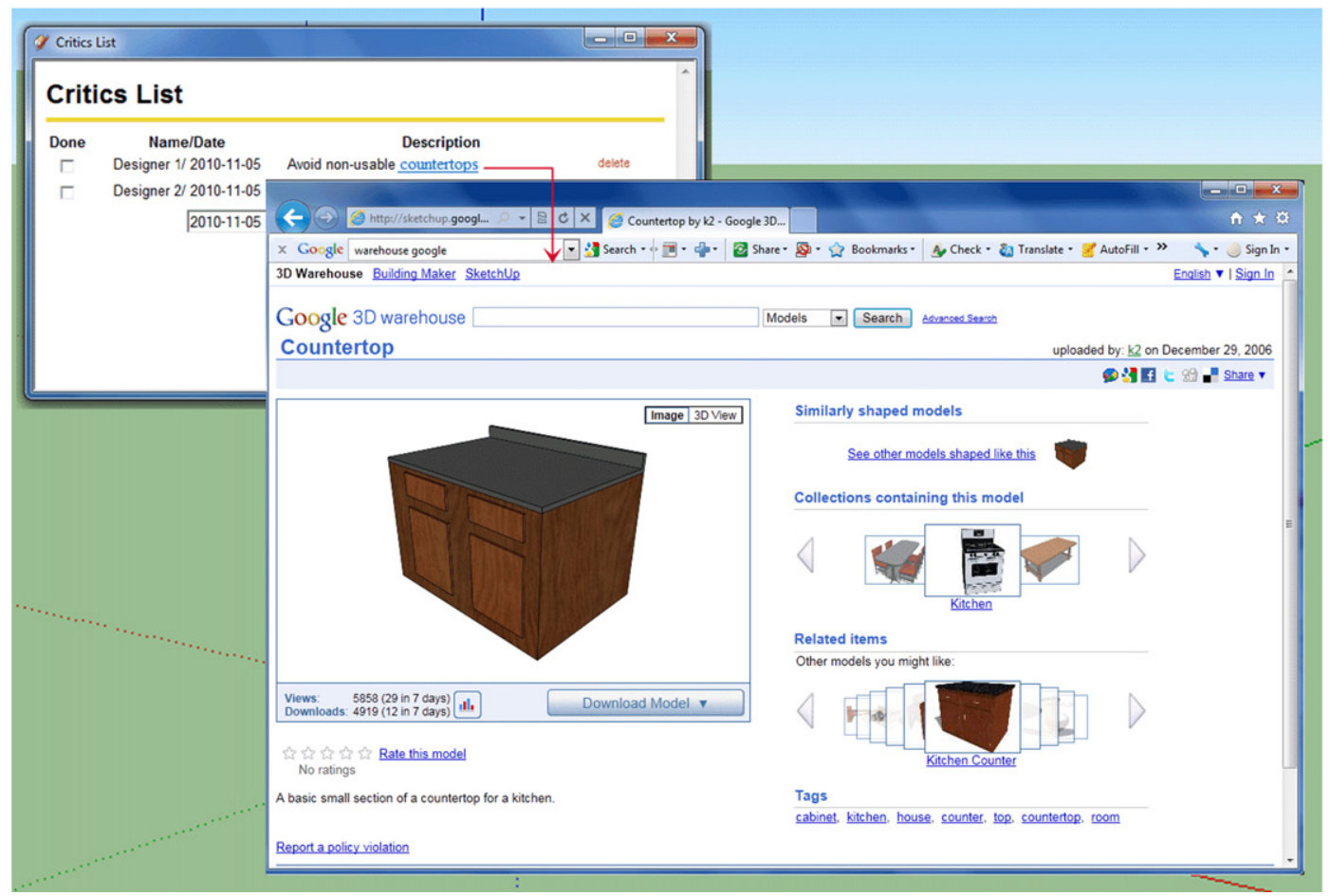

Fig. 7. An exemplary critic list interface (a) and a screenshot of a webpage (b) opened by clicking the wiki markup of 'countertops'.

alternatives to the Warehouse. The proposed ontology combines expert knowledge with the representation of how a universal problem would be ideally solved and enriched by means of semantic annotations of critics. Hence, this interface helps in building social network and exchanging information among designers in real time. Designer can upload the project to 3D Warehouse with the critic list; consequently it is then available for other designers to comment on. As the other designer completes the comments on the project and loads it to the Warehouse, an email alert informs the collaborative network members. A critic list item includes the date of the given critique, nick/name of the designer, description of the critique and the add/delete buttons (Fig. 7a). The description of the critique is a structured entity that organizes the information in the domain. The basic role of the ontologies in this case is to allow designers entering their comments in the form of html text with mark-up tags. Fig. 7b shows a screenshot of a webpage, which is opened by clicking the wiki markup of 'countertops' and represents exemplary images from countertop knowledge base of Google Warehouse (www.sketchup.com). Compared to the raw text documents, this capability of the tool provides support for the collaborative creation of knowledge and representation of data in a systematic and user friendly way. Moreover, the semantic data is enriched and extended with graphical and textual knowledge processing and representation.

\subsection{Universal design evaluation}

Universal design evaluation capability of the CAUD plug-in tool consists of the dimensional standards and the universal design checklist interfaces. The ontology here works as an evaluator. It 


\section{Universal Design Checklist}

\begin{tabular}{lll} 
Principle One/ Equitable use & Yes & No \\
\hline
\end{tabular}

1.a. Could all potential users use the kitchen in essentially the same way, regardless of differences in their abilities?

1.b. Could potential users use the kitchen without feeling segregated or stigmatized because of differences in personal capabilities?

1.c. Do potential users of the kitchen have access to all features of privacy, security, and safety, regardless of personal capabilities?

1.d. Does the kitchen appeal to all potential users?

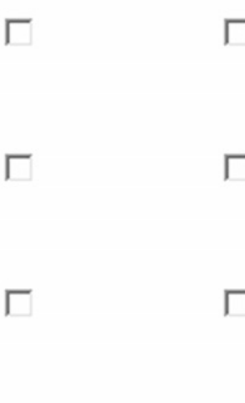

\section{Principle Two/ Flexibility in use}

2.a. Does the kitchen accommodate a wide range of individual preferences and abilities?

2.b. Can every potential user find at least one way to use the kitchen effectively?

2.c. Does the kitchen facilitate the user's accuracy and precision?

2.d. Does the kitchen provide adaptability to the user's pace?
-

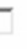

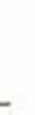


the user acceptance of the plug-in tool by using a 7-point Likert scale ranged from 'strongly agree' (7) to 'strongly disagree' (1) (for further details of the SAQ, see [2]).

Assessing the user acceptance of the plug-in tool is composed of three consecutive sessions that were conducted face-to-face and individually with respondents. Firstly, each respondent received $20 \mathrm{~min}$ of training on how to use the web dialogs and the dialog boxes of the plug-in tool. They watched a demonstration video, which showed the functionalities and capabilities of the tool. In the second session, the plug-in tool was installed into each respondent's own computer to conduct the task scenarios. The goal of the task scenarios is to involve the respondents in a kitchen design through the usage of the tool. After the tasks were completed, the participants were given the SAQ. For each respondent, it took approximately 15-20 min to complete the questionnaire. In addition to the questionnaire data, the respondents were encouraged to speak aloud while designing, especially when they run into trouble or engage with a thinking process. Furthermore, the observational data and comments about general use of the tool were recorded.

In general, the scores showed that the CAUD plug-in tool is acceptable ( 4 or above) and all the respondents have positive opinions about the tool. It is scored well on the usefulness with an average score 5.51, clarity with an average score 5.88, efficiency with an average score 5.63, support/help with an average score 5.13 and satisfaction with an average score 5.97. For usefulness, all the respondents found the facilities offered by the plug-in tool useful in supporting and enhancing universal design process. For clarity, the scores of all the statements were above 4 so that the tool was seen reasonably clear and understandable. For efficiency, the mean values of the statements were close to each other. The results and observations showed that all the respondents achieved the given tasks quickly within the SketchUp environment. The lowest score was obtained for the support/help because 10 of 15 respondents wanted to see a help tutorial within the tool. Thus, it is desirable to consider the development of a more comprehensive help system in the future, such as providing support to the user by tutoring, prompting the user in the right direction and explanations of what the tool is about and how the tool is to be used. Satisfaction has the highest mean value because 12 of 15 respondents were satisfied with the capabilities of the tool so that in the future it would be interesting to learn and experience more about the tool.

Finally, the respondents also developed suggestions for further improvement of the CAUD plug-in tool. Most of the architects (7 of 9) suggested that the 'Universal design checklist' interface could be made more dynamic and interesting. Having filled out the checklist, they would like to see the ratio information of yes/no questions, through which the tool could report the overall performance of a project in percentages. Then, with the resulting report it would be easier to compare the weaknesses or strengths of the project with other solutions. Much discussion is needed to mention the evaluation issue for checking performance and reliability analysis of the suggested tool. In this respect, as a future work we aim to employ qualitative techniques, such as the common process of running test cases through the proposed tool and comparing the tool's output with known results.

\section{Conclusion}

In this paper, we present a novel ontology-based approach for universal design concept generation. Today, universal design knowledge appears in various sources changing from technical documents to design representations [39]. However, CAD applications should provide knowledge representations that can flexibly adapt to the requirements of the projects [5]. Therefore, we devel- oped the CAUD plug-in tool that defines ontologies together with the iterative process of analysis-synthesis-evaluation operations. In Section 1, we proposed three explicit research questions and the answers to these questions are as follows:

1. Our solution to how to deal with design requirements, sequence of strategies and evaluation of alternative designs is achieved by identifying the existing sources of universal design data and integrating them to the requirements of analysis, synthesis and evaluation operations.

2. Ontologies are used to represent universal design database schemas. The ontological language enhances searching, retrieving and using universal design standards, guidelines and use cases within the SketchUp environment.

3. The feedback mechanism of the proposed plug-in tool is achieved through semantic wikis. Semantic wikis with annotations and markup tags could provide strong knowledge representations that do not interrupt designer's creative process. Its web-based and open nature allows the distribution of design process over a group of designers [5].

The CAUD plug-in tool with its above-explained capabilities coincide with the following five functional requirements of an ideal knowledge-based design support system [40]: (1) support and visualize the evolution of design development, (2) set up a creative support environment, (3) capable of knowledge management functions, (4) support a collaborative work and (5) conduct a design process with analysis, synthesis and evaluation operations.

To sum up, the cognitive needs of a designer for problem solving are highly related with the conducted design activities, and the successes of a designer in each of these activities are dependent on the employed design strategies [14]. Moreover, as psychologists acknowledged there are a number of benefits of using computer technologies to simulate cognitive process of problem solving [58]. In this respect, what is unique in our ontology is that both knowledge processing and representation is based on the most suitable design strategy and cognitive needs of designers in the conceptual design phase. Ontologies in the study provide an essential basis for enhancing designers' cognitive approach to successfully capturing, efficiently organizing, effectively representing and easily modeling of the universal design knowledge. Moreover, compared to the conventional approaches, the ontology-based approach helps to reduce the working time, increases confidence in generated solution, and contributes to the exploration of design alternatives in a short period of time. Therefore, the contribution of the CAUD plug-in tool into scientific knowledge is as follows: (1) the universal design knowledge domain is interfaced for the first time with an ontological knowledge-based approach without hindering the creativity of designer; (2) the plug-in tool overcomes the limitations in architectural design practice by providing an efficient management of universal design knowledge processing and representation. Our future work includes elaboration of an advanced CAUD plug-in tool with improved representation and reasoning capabilities. A higher level semantic web layer could be studied that allows more flexible mechanism for collaborative work and an advanced universal design knowledge processing within a wiki system. It would be also possible to extend the ontological language of the plug-in tool for different built environments as suggested by the respondents, who carried out the acceptability studies.

\section{References}

[1] Y. Afacan, Designing for an aging population: residential preferences of the Turkish elderly to age in place, in: P. Langdon, P.J. Clarkson, P. Robinson (Eds.), Designing Inclusive Futures, Springer, London, 2008, pp. 241-252. 
[2] Y. Afacan, A computer assisted universal design (CAUD) plug-in tool for architectural design process [online], Thesis (PhD), Bilkent University, Ankara, Turkey. Available from: <http://bliss.bilkent.edu.tr/blissweb.php?islem=2 \&dil=0\&d=bilkutup\&n=0405979>, 2008 (accessed 10.09.08).

[3] Y. Afacan, C. Erbug, Application of heuristic evaluation method by universal design experts, Applied Ergonomics 40 (4) (2009) 731-744.

[4] Y. Afacan, H. Demirkan, A priority-based approach for satisfying the diverse users' needs, capabilities and expectations: a universal kitchen design case, Journal of Engineering Design 21 (2-3) (2010) 315-343.

[5] J. Baumeister, J. Reutelshoefer, F. Puppe, KnowWE: a Semantic Wiki for knowledge engineering, Applied Intelligence (2010), in press, doi:10.1007/ s10489-010-0224-5.

[6] K. Becker, M. Vanzin, O3R: ontology-based mechanism for a human-centered environment targeted at the analysis of navigation patterns, Knowledge-Based Systems 23 (5) (2010) 455-470.

[7] R. Bracewell, K. Wallace, M. Moss, D. Knott, Capturing design rationale Computer-Aided Design 41 (3) (2009) 173-186.

[8] Canadian Human Rights Commission, International best practices in universal design: a global review, CD-ROM, Bety Dion Enterprises Ltd., Canada, 2006.

[9] G. Carrara, Y.E. Kalay, Past, present, future: process and knowledge in architectural design, in: G. Carrara, Y.E. Kalay (Eds.), Knowledge-based Computer-aided Architectural Design, Elsevier, Amsterdam, 1994, pp. 389396.

[10] G. Carrara, Y.E. Kalay, G. Novembri, Knowledge-based computational support for architectural design, in: G. Carrara, Y.E. Kalay (Eds.), Knowledge-Based Computer-Aided Architectural Design, Elsevier, Amsterdam, 1994, pp. 147204.

[11] P. Company, M. Contero, P. Varley, N. Aleixos, F. Naya, Computer-aided sketching as a tool to promote innovation in the new product development process, Computers in Industry 60 (8) (2009) 592-603.

[12] N. Cross, Engineering Design Methods, John Wiley and Sons, Chichester, 1989

[13] N. Cross, Designerly Ways of Knowing, Springer-Verlag Ltd., London, 2006.

[14] H. Demirkan, Generating design activities through sketches in multi-agent systems, Automation in Construction 14 (6) (2005) 699-706.

[15] Z. Dongmin, H. Dachao, X. Yuchun, A framework for ontology-based product design knowledge management, in: Proceedings of the 2010 Seventh International Conference on Fuzzy Systems and Knowledge Discovery, 2010 pp. 1751-1755.

[16] K. Dorst, N. Cross, Creativity in the design process: co-evolution of problemsolution, Design Studies 22 (5) (2001) 425-437.

[17] G. Fischer, A.C. Lemke, T. Mastaglio, A.I. Morch, The role of critiquing in cooperative problem solving, ACM Transactions on Information Systems 9 (2) (1991) 123-151.

[18] G. Fischer, K. Nakakoji, J. Ostwald, G. Stahl, T. Sumner, Embedding computerbased critics in the context of design, in: Proceedings of INTERCHI 93, 1993, pp. 157-164.

[19] U. Flemming, Case-based design in the SEED system, in: G. Carrara, Y.E. Kalay (Eds.), Knowledge-Based Computer-Aided Architectural Design, Elsevier, Amsterdam, 1994, pp. 69-94.

[20] G. Fricke, Successful individual approaches in engineering design, Research in Engineering Design 8 (3) (1996) 151-165

[21] M. Gaeta, F. Orciuoli, P. Ritrovato, Advanced ontology management system for personalised e-learning, Knowledge-Based Systems 22 (4) (2009) 292-301

[22] T.R. Gruber, A translation approach to portable ontologies, Knowledge Acquisition 5 (2) (1993) 199-220.

[23] Q. Guo, M. Zhang, Question answering based on pervasive agent ontology and Semantic Web, Knowledge-Based Systems 22 (6) (2009) 443-448.

[24] K. Hori, Concept space connected to knowledge processing for supporting creative design, Knowledge-Based Systems 10 (1) (1997) 29-35.

[25] Y.E. Kalay, The impact of information technology on design methods, products and practices, Design Studies 27 (3) (2006) 357-380.

[26] C. Kruger, N. Cross, Solution driven versus problem driven design: strategies and outcomes, Design Studies 27 (5) (2006) 527-548.

[27] T. Kurtoglu, M.I. Campbell, J.S. Linsey, An experimental study on the effects of a computational design tool on concept generation, Design Studies 30 (6) (2009) 676-703.

[28] D.Y. Kwon, M.D. Gross, E.Y. Do, ArchiDNA: an interactive system for creating 2D and 3D conceptual drawings in architectural design, Computer-Aided Design 41 (3) (2009) 159-172.

[29] B. Lawson, Cognitive strategies in architectural design, Ergonomics 22 (1) (1979) 59-68.

[30] D. Levine (Ed.), Universal design New York 2, IDEA Publications, New York, 2006.

[31] L.A. Liikkanen, M. Perttula, Exploring problem decomposition in conceptual design among novice designers, Design Studies 30 (1) (2009) 38-59.
[32] Y.C. Liu, T. Bligh, A. Chakrabarti, Towards an 'ideal' approach for concept generation, Design Studies 24 (4) (2003) 341-355.

[33] H.C. Lucas, Performance and the use of an information system, Management Science 21 (8) (1975) 908-919.

[34] R.L. Mace, Accessible Environments: Toward Universal Design, The Center for Universal Design Press, Raleigh, NC, 1991.

[35] M. Maguire, AQ and SAQ: pre- and post-test questionnaires for assessing user acceptance, HUSAT MemoHM1148, HUSAT Research Institute, Loughborough, June 2001.

[36] G.S. Mahalakshmi, T.V. Geetha, Argument-based learning communities, Knowledge-Based Systems 22 (4) (2009) 316-323.

[37] M.L. Maher, J. Poon, S. Boulanger, Formalising design exploration as coevolution: a combined gene approach, in: J.S. Gero, F. Sudweeks (Eds.), Advances in Formal Design Methods for CAD, Chapman-Hall, London, 1996, pp. $1-28$.

[38] K. Meniru, H. Rivard, C. Bedard, Specifications for computer-aided conceptual building design, Design Studies 24 (1) (2003) 51-71.

[39] J.L. Mueller, Case Studies on Universal Design, The Center for Universal Design, Raleigh, NC, 1997.

[40] E. Mulet, R. Vidal, Functional requirements for computer-based design support systems derived from experimental studies, Knowledge-Based Systems 19 (1) (2006) 32-42.

[41] G.J. Nalepa, Collective knowledge engineering with semantic wikis, Journal of Computer Science 16 (7) (2010) 1006-1023.

[42] E. Ostroff, Universal design: the new paradigm, in: F.E.W. Preiser, E. Ostroff (Eds.), Universal Design Handbook, McGraw-Hill, New York, 2001, pp. 1.11.12 .

[43] S. Ottosson, Qualified product concept design needs a proper combination of pencil-aided design and model-aided design before product data management, Journal of Engineering Design 9 (2) (1998) 107-119.

[44] I. Ozkaya, O. Akin, Requirement-driven design: assistance for information traceability in design computing, Design Studies 27 (3) (2006) 381-398.

[45] J.M. Porter, K. Case, R. Marshall, D. Gyi, R.S. Oliver, Beyond Jack and Jill': designing for individuals using HADRIAN, International Journal of Industrial Ergonomics 33 (3) (2004) 249-264.

[46] W. Preiser, Toward universal design evaluation, in: F.E.W. Preiser, E. Ostroff (Eds.), Universal Design Handbook, McGraw-Hill, New York, 2001, pp. 9.19.16 .

[47] L. Ringaert, User/expert involvement in universal design, in: F.E.W. Preiser, E. Ostroff (Eds.), Universal Design Handbook, McGraw-Hill, New York, 2001, pp. 6.1-6.8.

[48] J.E. Robbins, D.M. Hilbert, D.F. Redmiles, Extending design environments to software architecture design, Automated Software Engineering 5 (3) (1998) 261-290.

[49] N.F.M. Roozenburg, J. Eekels, Product Design: Fundamentals and Methods, John Wiley and Sons, Chichester, 1994.

[50] H.J. Rutherford, T.W. Maver, Knowledge-based design support, in: G. Carraram, Y.E. Kalay (Eds.), Knowledge-Based Computer-Aided Architectural Design, Elsevier, Amsterdam, 1994, pp. 243-268.

[51] D. Sánchez, M. Batet, D. Isern, Ontology-based information content computation, Knowledge-Based Systems, in press (Corrected Proof, Available online 10 October 2010).

[52] S. Schaffert, A. Gruber, R. Westenhaler, A Semantic Wiki for collaborative knowledge formation, in: Semantics 2005, Vienna, Austria, November 2005, pp. $1-15$.

[53] M.F. Story, Maximizing usability: the principles of universal design, Assistive Technology 10 (1) (1998) 4-12.

[54] M.F. Story, Principles of universal design, in: F.E.W. Preiser, E. Ostroff (Eds.), Universal Design Handbook, McGraw-Hill, New York, 2001, pp. 10.1-10.11.

[55] M.F. Story, J.L. Mueller, M. Montoya-Weiss, Progress in the development of universal design performance measures, in: Proceedings of the RESNA 2000 Annual Conference, 2000, pp. 132-134.

[56] M.F. Story, J.L. Mueller, M. Montoya-Weiss, Completion of universal design performance measures, in: Proceedings of the RESNA 2001 Annual Conference, 2001, pp. 109-111.

[57] J.P. Van Leeuwen, B. Vries, Modelling with features and the formalization of early design knowledge, in: Proceedings of the Third European Conference on Product and Process Modeling in the Building and Related Industries, 2000.

[58] Y. Wang, V. Chiew, On the cognitive process of human problem solving, Cognitive Systems Research 11 (1) (2010) 81-92.

[59] J. Ye, R.I. Campell, T. Page, K.S. Badni, An investigation into the implementation of virtual reality technologies in of conceptual design, Design Studies 27 (1) (2006) 77-97. 